\title{
MAMMALS OF THE UPPER HENTY RIVER REGION, WESTERN TASMANIA
}

\author{
by R.J. Taylor, S.L Bryant, D. Pemberton and T.W. Norton ${ }^{1}$
}

(with 3 tables and one text-figure)

TAYLOR, R.J., BRYANT, S.L., PEMBERTON, D. \& NORTON, T.W., 1985 (31:vii): Mammals of the

Upper Benty River Region, Western Tasmania. Pap.Proc. R. Soc. Tasm. 119:7-14.

https://doi.org/10.26749/rstpp.119.7 ISSN 0080-4703. Department of Zoology, University of

Tasmania, Hobart, Tasmania 7001 and ' Forestry Department, Australian National University,

Canberra, A.C.T. 2601, Australia.

A mammal survey was conducted in the Upper Henty River Region in western Tasmania. The area had been subject to much disturbance from mining, forestry and frequent fires and was covered by a maze of roads and tracks. Nineteen native species (including bats) were recorded. Four of the species listed in 1983 as occurring in the Lower Gord on Region, $80 \mathrm{~km}$ south of the present studyarea, were not recorded during our survey. It is considered that three of these species would probably have been found in the area with further searching. The fourth species, Mastacomys fuscus, is thought not to be present due to increased fire frequency in the sedgeland areas compared with the Lower Gord on Region. Potorous tridactylus is recorded for thefirst timefrom rainforest. Microhabitat selection by Rattus lutreolus and Pseudomys higginsi differed from that previously reported. Dist urbance from road construction led to the creation of a new food source for Thylogale billardierii. The ab undance of tracks in the a rea increased ease of movement for carnivorous mammals. Only one introduced species Felis catus, which is also known to occur in the Lower Gordon, was recorded. Disturbance had thus not led to an invasion of exotics.

Key Words: Tasmania, mammals, ecology, habitat disturbance effect.

\section{INTRODUCTION}

A surveyof the mammal fauna was conducted in the Upper Henty River Region in western Tasmania. The area surveyed is approximately $80 \mathrm{~km}$ north of the Lower Gordon Region which had been surveyed for mammals by Hocking and Guiler (1983). In contrast to the Lower Gordon Region, which is relatively undisturbed, the present study area has been subject to a long history of disturbance. Hocking and Guiler (1983) concluded that the hydro-electric power scheme proposed for the Lower Gordon Region would gravely affect the mammal population through habitat disruption and the invasion of exotics. The mammal survey conducted in the Upper Henty Region allowed some of these predictions to be examined.

Hocking and Guiler (1983) described the distribution of mammals in the Lower Gordon Region in relation to structural features of the vegetation. The present study allowed a re-exa mination of the distribution patterns of the mammals in relation to floristic vegetation categories.

\section{STUDY AREA}

The studyarea is located in the northern part of the South-West Conservation Area (fig. 1). Much of the land in this conservation zone has remained uninhabited and unexploited. The Henty

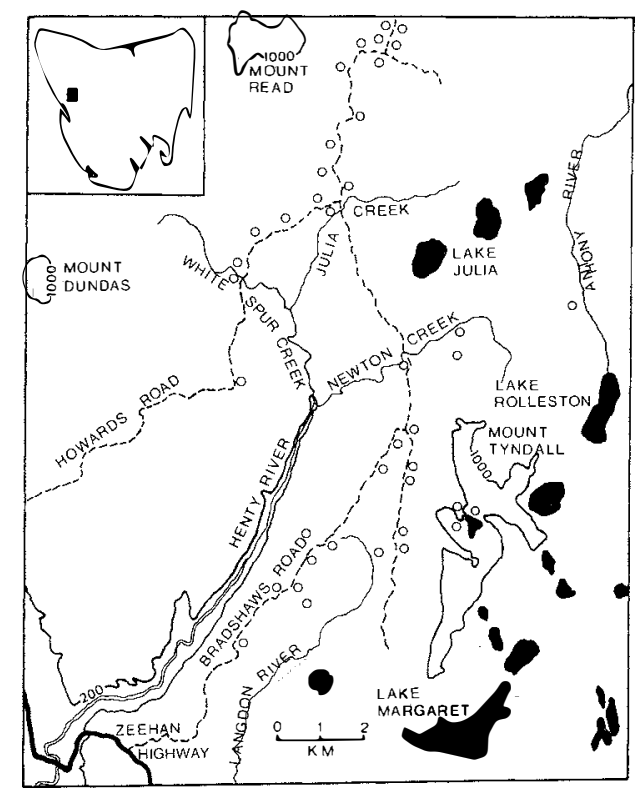

FIG 1. - Map of the study area. The position of trap sites is shown by open circles. Isobars for 200 and 1000 metres are indicated. Only the major roads and creeks are shown. 
River area has, however, been subject to substantial disturbance. Mineral exploration in the study area began in the 1880s and has accelerated over the past sixteen years. Many of the roads present were developed by mining companies. A system of grid lines has been cut across the area to facilitate exploration. Two campsites with tin huts are maintained in the area by mining commpanies. Test drilling is being conducted by both the Mines Department and private companies. Selective logging of rainforest followed the development of access into the area and led to the creation of a maze of snig tracks and log dumps (Calais \& Kirkpatrick 1983). Prescribed burning, mainly in the sedgeland areas, is conducted regularly by the Forestry Commission. The area is used for recreation by four wheel drive enthusiasts and trail bike riders. Gorse (Ulex europaeus), an exotic species, has become established along Howards Road, the most hea vily used track into the area. The development of a hydro-electric scheme began in the area after the survey was completed.

\section{Vegetation}

Five vegetation types are recognized. These are based on those listed for the area by Kirkpatrick $(1977,1983)$.

\section{Rainforest}

Forest or closed scrub dominated by various combinations of Nothofagus cunninghamii, $N$. gunnii, Atherosperma moschatum, Athrotaxis cupressoides, Eucryphia lucida, Anodopetalum biglandulosum. The understorey is usually open with the fern Blechnum wattsii and fallen logs being common and mosses covering much of the ground. This habitat encompasses the rainforest, scrub rainforest and mixed forest plant communities of Kirkpa trick (1983). Mixed forest is rainforest with scattered emergent eucalypts.

\section{Wet scrub}

Closed and open scrub and forest areas which are dominated variously by Leptospermum, Melaleuca, Acacia and Banksia. The undergrowth varies from dense leaf litter with no shrub layer to dense Gahnia grandis or Restio sp. with short shrubs being common.

\section{Eucalypt scrub}

Open-scrub or open-forest dominated by Eucalyptus spp. with understories not dominated by rainforest species. Common understorey species include Gahnia grandis, Bauera rubioides and Leptospermum spp.

\section{Sedgeland}

Heath or sedgeland with the dominants usually belonging to the Cyperaceae (particularly
Gymnoschoenus sphaerocephalus), Epacridaceae, Proteaceae, Myrtaceae or Restionaceae.

\section{Alpine}

Vegetation less than two metres tall composed of austral-montane species. The community consists of a mosaic of cushion plants, dwarf conifers, sclerophyll shrubs and herbs. The alpine area sampled was located on the Tyndall Ranges.

Disturbed areas dominated by Gahnia grandis were commonly found along the sides of roads particularly in rainforest. A mat of mosses and sedges was usually present on disturbed soil along the edges of roads and in old log dumps.

\section{METHODS}

The main survey was conducted between 6 and 16 November 1983. Four techniques were used to survey the mammal fauna: trapping, direct observation both by day and by night with the aid of a spotlight, analysis of hair samples from hair sampling tubes and from carnivore scats, and indirect evidence i.e. footprints and faeces. A further trapping period for bats and Antechinus swainsonii only, was conducted in rainforest between 11 and 21 January 1984.

Three sizes of trap were used for the terrestrial mammals. Elliot type A traps $(0.35 \times 0.1 \times 0.09 \mathrm{~m})$, baited with rolled oats and peanut butter were for the small mammals. The middle-sized traps $(0.55 \mathrm{x}$ $0.2 \times 0.2 \mathrm{~m}$ ) were baited with either apple and peanut butter to attract medium-sized herbivores such as Potorous tridactylus, or day old chicks to attract the medium-sized carnivores such as Dasyurus maculatus. The larger traps $(0.77$ or 0.55 x $0.3 \times 0.3 \mathrm{~m}$ ), baited with meat scraps, were set to catch larger carnivores i.e. Sarcophilus harrisii.

Traps were distributed over the area to obtain replicate samples in each of the different vegetation types. All Elliot and medium herbivore traps were placed off the tracks, inside the vegetation type being sampled. Sixty percent of the medium carnivore traps were placed on the sides of roads or creeks and the rest were placed in the vegetation. All large carnivore traps (except for the one trap in the alpine area) were placed on the side of roads. The location of trap sites is shown in figure 1 . The number of traps at each site varied from 2 to 30 . Each trap was separated by at least 10 metres but usually more. Most traps were set for eight consecutive nights in the one position. Those in the alpine area and in two of the sedgeland sites were set for three consecutive nights. A patch of hair was removed from animals captured so tha they could be recognized if recaptured. Recapture rates for Rattus lutreolus and Pseudomys higginsi 


\section{TABLE 1}

\section{Number of nights each type of trap was set and the number of hair tubes in each vegetation type.}

\begin{tabular}{lcccccc} 
& \multicolumn{7}{c}{ TYPE OF TRAP } \\
Vegetation & Elliot & $\begin{array}{c}\text { Medium } \\
\text { Herbivore }\end{array}$ & $\begin{array}{c}\text { Medium } \\
\text { Carnivore }\end{array}$ & $\begin{array}{c}\text { Large } \\
\text { Carnivore }\end{array}$ & Bat & Hair \\
Rainforest & $549^{\mathrm{A}}$ & 35 & 75 & 39 & $66^{\mathrm{B}}$ & 11 \\
Wet scrub & 224 & 84 & 32 & 16 & - & 2 \\
Eucalypt scrub & 294 & 46 & 40 & 38 & 6 & 11 \\
Sedgeland & 726 & 6 & 28 & 16 & - & 3 \\
Alpine & 207 & 6 & 12 & 3 & - & - \\
Totals & 2000 & 101 & 187 & 112 & 72 & 27
\end{tabular}

${ }^{A}$ An additional 355 trap nights with Elliots in rainforest were undertaken during January. These have not been included above as only data on $A$. swainsonii were collected at this time.

${ }^{\mathrm{B}} 11$ trap nights during November, the rest during January.

in the different vegetation types were similar, so the a nalysis of habitat preferences for these two species was based on capture rates and not on the number of individuals caught.

Bats were captured using harp traps (Tidemann \& Woodside 1978) placed on narrow tracks. Hair sampling tubes (Suckling 1978), baited with a mixture of rolled oats and syrup, were used to try to detect the presence of small arboreal species which are difficult to trap or observe. Some of the tubes had a funnel glued on to each end to increase the range of sizes of animals able to be detected (Winnett \& Degabriele 1982). The tubes were placed on logs or in the branches of trees or shrubs.

The number of trap nights for each type of trap in each vegetation type is given in table 1 . A total of 12 hours spotlighting was undertaken: 8 hours from a vehicle and 4 hours on foot. Chance observations of mammals made during the day were recorded as were any footprints or faecal pellets found. Faecal pellets were identified on the basis of reference material and experience gained elsewhere in the state (especially by D.P. with carnivores). The few pellets which could not be confidently identified were not included. Most of the carnivorous mammals caught were kept overnight and any faeces produced were collected. The hair samples from hair tubes and the faecal pellets were identified using the methods of Brunner and Coman (1974).

\section{RESULTS \\ Species Recorded and Their Habitat Preferences}

\section{Monotremes}

Tachyglossus aculeatus - Only one animal was seen, on the side of a road in rainforest.

Ornithorhynchus anatinus - One individual was seen in Lake Julia (W. Fulton, pers. comm.). Little time was spent searching for this species and it is likely to occur within many of the lakes and rivers in the region.

\section{Family Dasyuridae}

\section{Marsupials}

Sarcophilus harrisii - Four individuals were captured, two of which were recaptured. The records for this species for different vegetation types were: rainforest -4 captures, 2 sets of prints, 2 sets of faecal pellets; wet scrub -1 capture, 1 set of faecal pellets; eucalypt scrub - 1 capture, 3 sets of faecal pellets; alpine -2 sets of faecal pellets.

Dasyurus viverrinus and D. maculatus Both species were caught in the large and medium carnivore traps. The number of captures in the 
different vegetation types for $D$. viverrinus was rainforest 0 , wet scrub 1 , eucalypt scrub 3 (all of the same individual), sedgeland 1 , alpine 2 (caught in Elliot traps) and for D. maculatus was rainf orest 3 , wet scrub 2 , eucalypt scrub 1 , sedgeland 0 , alpine 0 . Three $D$. viverrinus, all on roads through sed geland areas, were seen during spotlighting and faecal pellets from this species were found in sedgeland and a footprint was found in the alpine area. It thus appears that the two species differ in their distribution among vegetation types with $D$. viverrinus avoiding rainforest and $D$. maculatus avoiding sedgeland and alpine habitats.

Antechinus swainsonii - In January, one juvenile $A$. swainsonii was captured during 355 trap nights in rainforest. No $A$. swainsonii were caught in November.

Antechinus minimus -- Only one individual, a female with six pouch young, was trapped. This animal was found in wet closed sedgeland near a small creek. A dense layer of Melaleuca, 1.8 metres tall, was present. Bauera, Sprengelia, Gahnia, Restio, mosses and lichens were present in the undergrowth. Gymnoschoenus sedgelands occurred twenty metres from the trap site.

\section{Family Macropodidae}

Potorous tridactylus -- One individual was trapped in rainforest and two were seen crossing a road through rainforest. Droppings of this species were also found in rainforest.

Thylogale billardierii - Records for $T$. billardierii (table 2) indicate its presence in all vegetation types. Most individuals were seen feeding near the edges of roads, in clearings or in drainage cuttings where a dense mat of mosses and sedges covered the disturbed ground surface.

Macropus rufogriseus - One individual was seen on a road in an area of wet scrub.

\section{Family Vombatidae}

Vombatus ursinus - One individual was seen, during spotlighting, in open sedgeland. The number of sets of faecal pellets recorded in each habitat was: wet scrub 1 ; eucalypt scrub 5 ; sedgeland 11 (majority in open areas) and alpine many more than 50. This species was thus most abundant in areas with relatively open undergrowth, especially in alpine vegetation.

\section{Family Peramelidae}

Isoodon obesulus - One individual was trapped in closed sedgeland and one individual was seen in open sedgeland.

\section{Family Phalangeridae}

Pseudocheirus peregrinus - During spotlighting nine individuals were seen in wet scrub (3 in tall Banksia and the rest in groves of tall Leptospermum) and three were seen in eucalypt scrub (with Leptospermum in the understorey). Two nests were found in tall Banksia in wet scrub.

\section{Eutherians}

\section{Family Muridae}

Rattus lutreolus - Rattus lutreolus was the most common and widespread mammal species in the study area. There were significant differences in the density of $R$. lutreolus among vegetation types (table 3: $\quad 2=48, \mathrm{df}=4, \mathrm{p}<0.001$ ). The density of $R$. lutreolus in rainforest, wet scrub and eucalypt scrub was not significantly different. Population density in alpine areas was low. In eucalypt scrub four captures of two individuals were made in an Elliot trap placed one metre above the ground in a Banksia shrub. A sample of $R$. lutreolus hair was also found in a hair tube in a Banksia shrub in eucalypt scrub.

For sedgeland, the density of $R$. lutreolus in area s with shrubs 1.3 metres or taller was compared

TABLE 2

Total number of captures and an index of density (number of captures/100 trap nights) for Rattus lutreolus and Pseudomys higginsi in each vegetation type.

\begin{tabular}{lcccc} 
Vegetation & \multicolumn{2}{c}{ Rattus } & \multicolumn{2}{c}{ Pseudomys } \\
Type & $\begin{array}{c}\text { No. of } \\
\text { Captures }\end{array}$ & $\begin{array}{c}\text { Density } \\
\text { Index }\end{array}$ & $\begin{array}{c}\text { No. of } \\
\text { Captures }\end{array}$ & $\begin{array}{c}\text { Density } \\
\text { Index }\end{array}$ \\
Rainforest & 68 & 12.4 & 55 & 10.0 \\
Wet scrub & 27 & 12.1 & 8 & 3.6 \\
Eucalypt scrub & 47 & 16.0 & 10 & 3.4 \\
Sedgeland & 43 & 5.9 & 18 & 2.5 \\
Alpine & 1 & 0.5 & 1 & 0.5
\end{tabular}


TABLE 3

\section{Summary of the status and habitat preferences of each of the mammal species recorded in the study area.}

For relative abundance, the greater the number of + the greater were the number of records obtained for the species within that vegetation type. Abundance within a vegetation type is not directly comparable between species. 'Pr' (present) indicates the species occurs in the vegetation type but at a much reduced density compared with other areas. '?'indica tes the species may occur in this vegetation type. The platypus (an aquatic animal) is not included.

\begin{tabular}{|c|c|c|c|c|c|c|}
\hline SPECIES & $\begin{array}{l}\text { STATUS } \\
\text { WITHIN } \\
\text { THE } \\
\text { STUDY } \\
\text { AREA }\end{array}$ & Rainforest & $\begin{array}{r}\text { REATIVE } \\
\text { VEG } \\
\text { Wet scrub }\end{array}$ & $\begin{array}{l}\text { BUNDAN } \\
\text { TATION } 7 \\
\text { Eucalypt } \\
\text { scrub }\end{array}$ & $\begin{array}{l}\text { CE WITHIN } \\
\text { YPES } \\
\text { Sedgeland }\end{array}$ & Alpine \\
\hline Tachyglossus aculeatus & uncommon & + & $?$ & $?$ & & + \\
\hline Sarcophilus harrisii & common & + & + & ++ & & + \\
\hline Dasyurus maculatus & common & +++ & +++ & + & & \\
\hline D. viverrinus & common & & + & + & ++ & ++ \\
\hline Antechinus swainsonii & uncommon & + & & & & \\
\hline Antechinus minimus & uncommon & & & & + & \\
\hline Potorous tridactylus & uncommon & + & & & & \\
\hline Thylogale billardierii & abundant & ++++ & +++ & ++ & +++ & + \\
\hline Macropus rufogriseus & uncommon & & + & $?$ & & \\
\hline Vombatus ursinus & common & & + & ++ & +++ & ++++ \\
\hline Isoodon obesulus & uncommon & & & & + & \\
\hline Pseudocheirus peregrinus & common & & +++ & + & & \\
\hline Rattus lutreolus & abundant & +++ & +++ & ++++ & ++ & $\mathrm{Pr}$ \\
\hline Pseudomys higginsi & abundant & ++++ & ++ & ++ & + & $\mathrm{Pr}$ \\
\hline Eptesicus regulus & common & ++ & $?$ & $?$ & & \\
\hline Eptesicus sagittula & uncommon & + & $?$ & $?$ & & \\
\hline Chalinolobus morio & uncommon & + & ? & ? & & \\
\hline Nyctophilus geoffroyi & common & $++t$ & $?$ & $?$ & & \\
\hline Felis catus & common & ++ & + & $+t$ & & \\
\hline
\end{tabular}

with that for areas with no shrubs or with shrubs less than 1.3 metres tall. These two types of sedgeland are referred to as closed and open respectively and would be representative of different regenerative ages after fire. Density in closed areas (11.5 captures/100 trap nights) was significantly greater $(2=30, \mathrm{df}=1, \mathrm{p}<0.001)$ than in open a reas ( 1.5 captures/ 100 trap nights). The density of $R$. lutreolus in closed sedgeland is thus similar to that in the rainforest and scrub areas.

In wet scrub, three undergrowth types were recognized. The first type was an open understorey with dense litter present under tall Leptospermum or Banksia, the second type was a typical eucalypt scrub understorey including Gahnia, Bauera and Leptospermum, and the third type was similar to the second but with Restio replacing Gahnia resulting in a more open undergrowth. The density of $R$. lutreolus in these three undergrowth types was not uniform ( $2=5.1$, df $=1, \mathrm{p}<0.05)$. Density in the Restio undergrowth (2.1 captures) 100 trap nights) was lower than in the litter undergrowth ( 14.5 captures/ 100 trap nights) or in the Gahnia undergrowth (15.2 captures/100 trap nights).

A dense stand of Gahniagrandis was present on the disturbed edge of most of the roads through rainforest. The Elliot traps in rainforest were usually placed near this disturbed edge or occasionally in it. Areas trapped where this disturbance did not occur were above steep road cuttings or in areas isolated from roads. The density of $R$. lutreolus near disturbed areas (14.1 captures/ 100 trap nights) was significantly greater ( $2=6.8, \mathrm{df}$ $=1, p<0.01)$ than for areas not associated with these disturbed areas ( 3.4 captures/ 100 trap nights).

Pseudomys higginsi $-P$. higginsi was the second most commonly trapped mammal in the study area. As with $R$. lutreolus, it occurred in all vegetation types but density varied between them (table 3: $\quad 2=51, \mathrm{df}=4, \mathrm{p}<0.001$ ). The density of $P$. higginsi in wet scrub, eucalypt scrub and sedgeland was not significantly different. Density in 
rainforest was nearly three times greater than in the other areas whereas density in alpine areas was markedly less. One individual was captured in an Elliot trap placed above the ground in a Banksia shrub in eucalypt scrub.

In sedgeland, density of $P$. higginsi in closed areas ( 2.8 captures/ 100 trap nights) was not significantly different from that for open areas $(2.2$ captures/100 trap nights). The number of captures in wet scrub was too small for further analysis. For rainforest, the density of $P$. higginsi near dist urbed areas (10.6 captures/100 trap nights) was not significantly different from that for areas isolated from disturbance (6.8 captures/100 trap nights).

\section{Family Vespertilionidae}

Trapping for bats was conducted in eucalypt scrub and rainforest during November and in rainforest only during January. No bats were caught in eucalypt scrub. During November three Eptesicus sagitlula (27/100 trap nights) and one Chalinolobus morio (9/100 tra p nights) were caught in rainforest. During January 2 Eptesicus sagittula (4/100 trap nights), 9 Eptesicus regulus (16/100 trap nights) and 20 Nyctophilus geoffroyi $(36 / 100$ trap nights) were captured. Two of the same trap sites were used in both November and January. In November no $N$. geoffroyi were caught but in January $N$. geoffroyi were regularly captured at one of these sites.

\section{Family Felidae}

Felis catus - Three individuals were caught, one in rainforest, one in wet scrub and one in eucalypt scrub. One a nimal was seen on a road during spotlighting in eucalypt scrub. Two sets of faecal pellets were found, one in eucalypt scrub and one in rainforest.

\section{The Mammal Community}

A total of 19 native and one introduced mammal species were positively recorded in the study area. A summary of the status and habitat preferences for these species within the study area is given in table 3 . The number of terrestrial species recorded in each of the vegetation types does not differ markedly (rainforest 8 , wet scrub 10 , eucalypt scrub 9, sedgeland 7, alpine 6). Most species occurred in more than one vegetation type, however Antechinus swainsonil and Potorous tridactylus were only recorded from rainforest and $A$. minimus and Isoodon obesulus were found only in sedgeland. Macropus rufogriseus and Tachyglossus aculeatus were also recorded in only one vegetation type However, based on previous findings (e.g. Green 1973, Hocking \& Guiler 1983), it is likely that these two species occur in a wider range of vegetation types.

\section{DISCUSSION}

The 19 native species recorded in the study area represent $56 \%$ of the indigenous mammal species of Tasmania and $58 \%$ if bats are excluded. This compares with the $73 \%$ of the mammal fauna (excluding bats) which were found by Hocking and Guiler (1983) to occur in the Lower Gordon region. Four of the mammal species which were recorded from the Lower Gordon region by Hocking and Guiler were not found in the present study area. They a re Sminthopsis leucopus, Cercartetus nanus, Hydromys chrysogaster and Mastacomys fuscus.

Sminthopsis leucopus has been recorded from a wide range of habitats being widely distributed but rare (Green 1973). In Tasmania, factors determining the presence of this species in an area are little understood. The specimens of Cercartetus nanus found during the Lower Gordon survey were in pits dug to determine soil profiles (Hocking \& Guiler 1983). Green (1973) considers rainforest to be the preferred habitat of $C$. nanus. It is likely that $C$. nanus is present in the study area but not recorded because of the difficulty of detecting this species. Hocking and Guiler (1983) trapped one Hydromys chrysogaster on the banks of the Gordon River during their survey. No Hydromys were caught by us in the carnivore traps placed beside the major creeks in the area. However it is possible that this species occurs in the larger rivers and the many lakes in the area. In Tasmania Mastacomys fuscus occurs mainly in sedgeland (Green 1973). In the Lower Gordon region Hocking and Guiler (1983) recorded three $M$. fuscus, all from an area of mature closed sedgeland which had been last burnt in about 1940 . It is possible that suitable habitat for $M$. fuscus does not exist in the study area as the sedgelands are subject to regular firing. Areas of well developed closed hummock sedgeland with emergent shrubs were not found.

The habitat preferences of most of the mammals were similar to that reported by others (e.g. Green 1973, Hocking \& Guiler 1983). However, for three species Potorous tridactylus, Rattus lutreolus and Pseudomys higginsi) habitat preferences differed from those previously reported. P. tridacty/us has been recorded from sclerophyll forests, low scrub and heathland where a thick ground cover is present (Heinsohn 1968, Johnston 1983). In the present study area it was found only in rainforest. One of the rainforest sites at which $P$. tridacty/us was recorded was near other vegetation types but this was not the case for the other two sites. This is the first recording of $P$. tridacty/us from rainforest in Tasmania. Its presence in this vegetation type, where ground cover is open, is surprising. No $P$. tridactylus were recorded by Hocking and Guiler (1983) in the Lower Gordon basin. 
Rattus lutreolus is predominantly herbivorous and captures have been shown to be correla ted with the abundance of monocotyledons, both in Tasmania (Norton 1983) and in Victoria (Braithwaite \& Gullen 1978). Since the abundance of monocotyledons in areas of wet scrub containing an open undergrowth with litter is low, the high density of $R$. lutreolus in these areas is unexpected. The low density of $R$. lutreolus in a reas of wet scrub with a Restio undergrowth, where monocotyled ons are abundant, is similarly surprising.

Hocking and Guiler (1983) captured Pseudomys higginsi in a wide range of vegetation types in the Lower Gordon region, but only where the undergrowth was devoid of cover within $0.5 \mathrm{~m}$ of the ground. P. higginsi also occurred in a range of vegetation types in the present study area, however, the undergrowth in which this species was capt ured covered a range of densities from very open to very dense. The distribution of $R$. lutreolus and $P$. higginsi differed both among vegetation types and with different undergrowth types within the same vegetation type. These differences may be related to differences in the abundance of food present for the two species in each vegetation type. $P$. higginsi probably includes more insects, lichen and bryophytes in its diet than does $R$. lutreolus (Murray 1980, Green 1983, Norton 1983).

This survey of the mammals occurring in alpine habitat is the first reported for Tasmania. Alpine had the fewest number of mammal species of any of the vegetation types in the region. Most of the species found here were also low in abundance. However, based on faecal pellet counts, Vombatus ursinus appears to occur at its greatest densities in alpine vegetation. Newsome et al. (1983) also report higher densities of $V$. ursinus in alpine vegetation compared with lowland forests in New South Wales. The area of alpine vegetation sampled was small and more extensive surveys of this habitat need to be undertaken, especially in the Central Plateau.

The survey of bats is the first reported for western Tasmania. Four of the eight species of Tasmanian bats were collected in the study area. No bats were captured in eucalypt scrub, probably because of the lack of a suitable flyway situation needed for the harp traps to be effective. Nyctophilus geoffroyi and Eptesicus regulus have been caught in wet scrub and eucalypt scrub around Melaleuca on Bathurst Harbour (M. Schulz \& K. Menkhorst, pers. comm.). The diversity of bats occurring in forests in eastern Tasmania is usually greater than in the present study area (O'Neill 1984).

The larger carnivorous ma mmals Sarcophilus harrisii, Dasyurus maculatus, D. viverrinus and Felis catus, were only ca ught along a road or track or beside a creek despite $40 \%$ of the traps being placed in the vegetation. The development of a maze of roads and tracks may thus have increased the ease of movement for these species in the study a rea. In the Lower Gordon River region, Hocking and Guiler (1983) concluded that $S$. harrisii was confined to areas bordering the major rivers. This was not the case in the present study area where the system of roads and tracks have allowed $S$. harrisit to range more widely. The effect of these differences in movement patterns on the carnivore populations and on predation levels would be worthy of further investigation.

Dasyurus maculatus and $F$. catus were found to have similar habitat preferences and the diet of both species probably consists of birds and small mammals (Edgar 1983, Taylor, unpubl. data). These similarities suggest that competition may be occurring between the two species.

The clearing of vegetation and top soil from along roadsides and in log dumps has allowed a dense mat of sedges and mosses to develop in these areas. The majority of Thylogale billardierii seen during the survey were feeding in these moss and sedge areas, which may represent a new source of food for the pademelons. It is not known, however, whether this increased food supply has led to increased numbers of $T$. billardierii.

Hocking and Guiler (1983) warned that disturbance in the Lower Gordon region might lead to the invasion of exotics. Increased disturbance in the Henty Region has not resulted in the permanent colonization of the area by the introduced rodents Rattus rattus and Mus musculus. Personnel from one of the mining companies reported "mice" to have been abundant in and around the huts at the Julia Creek camp in the summer of 1982. No mice were trapped around the huts during this survey. If these mice were in fact introduced species they have not succeeded in colonizing the native vegetation even in the areas of disturbance.

Those small mammals which utilise sedgelands, Antechinus minimus, Isoodon obesulus, Mastacomys fuscus, and Rattus lutreolus, seem to prefer closed sedgeland (Hocking \& Guiler 1983, this study). In the Upper Henty region, sed gelands are burnt frequently as part of the Forestry Commission's management program. This has resulted in a predominance of open sedgeland with low population levels of these species. M. fuscus is an extreme example of this, probably being excluded from the area due to its preference for the very old seral stages of post-fire succession in sedgeland (Hocking \& Guiler 1983).

The frequency and intensity of fire in the area will influence the abundance of different successional stages in the vegetation (Jackson 1968, 
Brown \& Podger 1982). Many of the mammal species in the region have been found to be present only within a restricted range of succession stages (Hocking \& Guiler 1983, this study), hence fire frequency will also influence the composition of the mammal fauna. Fire management will thus need to be an important component of any management plan for the South-West World Heritage Area.

\section{ACKNOWLEDGEMENTS}

We would like to thank Greg Hocking for his patience with our many inquiries regarding the Lower Gordon mammal survey, Dr. Jamie Kirkpatrick for discussions on the vegetation of the area and Alastair Sharp-Paul and Carl Mahoney for logistical help. The Tasmanian Forestry Commission and National Parks and Wildlife Service lent mammal traps. Greg Hocking and Dr. Stuart Halse commented on a previous draft of this paper. This study was supported by the HydroElectric Commission and the Forest Ecology Research Fund.

\section{REFERENCES}

BRAITHWAITE, R.W. \& GULLAN, P.K., 1978: Habitat selection by small mammals in a Victorian heathland. Aust. J. Ecol. 3: 109-127.

BROWN, M.J.\& PODGER, F., 1982: On the apparent anomaly between observed and predicted percentages of vegetation types in south-west Tasmania. Aust. J. Ecol. 7: 203-205.

BRUNNER, H. \& COMAN, B.J., 1974: THE IDENTIFICATION OF MAMMALIAN HAIR. Inkata Press, Melbourne.

CALAIS, S.S. \& KIRKPATRICK, J.B., I983: Tree species regeneration after logging in temperate rainforest, Tasmania. Pap. Proc. $R$. Soc. Tasm. 117: 77-83.

EDGAR, R., 1983: Spotted-tailed quoll, Dasyurus maculatus. In Strahan, R. (Ed.): COMPLETE BOOK OF AUSTRALIAN MAMMALS. Angus and Robertson, Sydney, 18-19.

GREEN, R.H., 1973: THE MAMMALS OF TAS$M A N I A$. Foot and Playsted, Launceston.

GREEN, R.H., 1983: Long-tailed mouse, Pseudomys higginsi. In Strahan, R. (Ed.): COMPLETE BOOK OF AUSTRALIAN MAMMALS. Angus and Robertson, Sydney, 396-397.
HEINSOHN, G.E., 1968: Habitat requirements and reproductive potential of the macropod marsupial Potorous tridactylus in Tasmania. Mammalia 32: $30-43$.

HOCKING, G.J.\& GUILER, E.R., 1983: The mammals of the Lower Gordon River Region, south-west Tasmania. Aust. Wildl. Res. 10: 1-23.

JACKSON, W.D., 1968: Fire, air, earth and water - an elemental ecology of Tasmania. Proc. Eco. Soc. Aust. 3: 9-16.

JOHNSTON, P.G., 1983: Long-nosed potoroo, Potorous tridactylus. In Strahan, R. (Ed.): COMPLETE BOOK OF AUSTRALIAN MAMMALS. Angus and Robertson, Sydney, 181

KIRKPATRICK, J.B., 1977: Native vegetation of the West Coast region of Tasmania. In Banks, M.R. \& Kirkpatrick, J.B. (Eds.): $L A N D S C A P E A N D$ $M A N$. Royal Society of Tasmania, Hobart, $55-80$.

KIRK PATRICK, J.B. 1983: VEGETATION AND HIGHER FLORA OF THE REGION AFFECTED BY THE HENTY-ANTHONY SCHEME. Unpublished report, Hydro-Electric Commission, Hobart.

MURR AY, P.A., 1980: WET SCLEROPHYLL HABITAT UTILIZATION BY SMALL MAM$M A L S$. Unpublished Honours thesis, University of Tasmania.

NEWSOME, A.E., CORBETT, L.K. \& CATLING, P.C., 1983: The feeding ecology of the dingo II. Dietary and numerical relationships with fluctuating prey populations in south-eastern Australia. Aust. J. Ecol. 8: 345-366.

NORTON, T.W., 1983: HABITAT UTILIZATION BY SM ALL MAMMALS IN NORTH EASTERN TASMANIA. Unpublished Honours thesis, University of Tasmania.

O'NEILL, M G 1984: STRUCTURE AND COMPO SITION OF TASMANIAN BAT COMMUNITIES. Unpublished Honours thesis, University of Tasmania.

SUCKLING, G.C., 1978: A hair sampling tube for the detection of small mammals in trees. Aust. Wildl. Res. 5: 249-252.

TIDEMANN, C.R. \& WOODSIDE, D.P., 1978: A collapsible bat trap and a comparison of results obtained with the trap and with mist-nets. Aust. Wildl. Res. 5: 355-362.

WINNETT, G. \& DEGABRIELE, R., 1981: A hair sampling tube for the detection of small and medium-sized mammals. Aust. Mammal. 5: 143-145. 